\title{
Análise econômica da produção de ovinos em lotação rotativa em pastagem de capim tanzânia (Panicum maximum (JACQ))
}

\author{
Maria de Fátima Vidal ${ }^{1}$ \\ Rodrigo G. da Silva ${ }^{2}$ \\ José N. Miranda Neiva ${ }^{3}$ \\ Magno José D. Cândido ${ }^{4}$ \\ Divan Soares da Silva ${ }^{5}$ \\ Márcio José Alves Peixoto ${ }^{6}$
}

RESUMO: A ovinocaprinocultura possui elevada importância socioeconômica no Nordeste, entretanto, o baixo potencial genético dos rebanhos, associado à escassez de pastos na estação seca, condiciona baixos índices de produtividade e rentabilidade. A formação de pastagem cultivada é uma forma de nivelar a capacidade de suporte durante o ano. $\mathrm{O}$ trabalho proposto objetiva aumentar a produtividade, expandir a renda e incentivar o produtor a investir em novas técnicas produtivas. Foram utilizados 100 ovinos mestiços (Santa Inês x SRD) e empregados três períodos de descanso do pasto: tratamento 1 - tempo para formação de 1,5 folha por perfilho em média; tratamento 2 - tempo para formação de 2,5 folhas, e tratamento 3 - tempo para formação de 3,5 folhas. A análise foi feita com base em 1,3 e 5 hectares com utilização de cerca de tela e elétrica. Foram utilizadas como medidas de eficiência: relação benefício custo,

\footnotetext{
${ }^{1}$ Mestre em Economia Rural, Banco do Nordeste do Brasil. fatimavidal@bnb.gov.br

${ }^{2}$ Eng. Agrônomo, Mestre em Zootecnia, Professor da Faculdade de Tecnologia CENTEC - Sertão Central. rodrigogregorio@hotmail.com

${ }^{3}$ Doutor em Zootecnia, Professor Associado da Universidade Federal do Tocantins, Escola de Medicina Veterinária e Zootecnia, Campus de Araguaína-TO. araguaia2007@gmail.com ${ }^{4}$ Professor adjunto do Departamento de Zootecnia, Universidade Federal do Ceará. mjdcandido@gmail.com

${ }^{5}$ Professor adjunto do Departamento de Zootecnia, Universidade Federal da Paraíba. divan@cca.ufpb.br

${ }^{6}$ Engenheiro Agrônomo, Mestre em Zootecnia e Doutorando em Zootecnia. Área de Forragicultura e Pastagens na Universidade Federal do Ceará. marciojose8@hotmail.com
} 
valor presente líquido, taxa interna de retorno, e análise de sensibilidade. O tratamento com 2,5 folhas com exploração de no mínimo 5 hectares apresentou o melhor resultado econômico, biológico e ambiental. Para que haja retorno econômico há necessidade de utilização de animais de ótimo potencial genético e de se explorar áreas superiores a 5 hectares.

Palavras-chave: Análise econômica, ovinos, pastagem rotativa.

\title{
Classificação JEL: Q19
}

\begin{abstract}
The breeding of ovine and caprine possess high partner-economic importance in the Northeast, however, the low genetic potential of the herds, as well as the scarcity of pastures during the dry season, limits the productivity and lucrativeness indices to a low level. The use of cultivated pastures is a way to maintain in high level the carrying capacity of the pasture over the year. This work was conducted with the aim of increase the productivity, expand the income and stimulate the producer to invest in new productive techniques. 100 Sem Raça Definida sheep and three periods were used. The rest period consisted of: treatment 1 - time for expansion of 1.5 new leaves per tiller; treatment 2 - time for expansion of 2.5 new leaves per tiller and treatment 3 - time for expansion of 3.5 new leaves per tiller. The analysis considered the use of 1, 3 or 5 hectares of pasture, fenced by campestre screen or electric fence. The efficiency indices adopted were: benefit cost relation, liquid present value, return internal tax, and sensitivity analysis. The 2.5 leaves rest period exploring at least 5.0 hectares presented best performance, in terms economics, biological and environmental. So, to promote economic return, it is necessary to use sheep of higher genetic potential and pastures areas above 5.0 hectares.
\end{abstract}

Key words: Economic analysis, sheep, intermittent stocking.

Jel Classification: Q19

\section{Introdução}

A ovinocaprinocultura é uma atividade econômica explorada em todos os continentes, está presente em áreas sob as mais diversas ca- 
racterísticas climáticas, edáficas e botânicas. No entanto, somente em alguns países a atividade apresenta expressão econômica, sendo, na maioria dos casos, desenvolvida de forma empírica e extensiva, com baixos níveis de tecnologia. No Nordeste brasileiro desempenha papel primordial no suprimento alimentar e geração de renda, no entanto, o baixo potencial genético dos rebanhos, associado à escassez de pastos na estação seca, às práticas de manejo inadequadas, às precárias condições sanitárias, às graves limitações zootécnicas e de assistência técnica, além das imperfeições de mercado, concorre para os baixos índices de produtividade e de rentabilidade.

A produtividade animal é função do potencial genético de produção e do meio onde ele está inserido, a alimentação é o mais importante fator do meio. Para aumentar a produtividade animal é primordial a disponibilização de alimento de qualidade. As pastagens nativas, no modo de produção atual, constituem a principal e, praticamente, exclusiva fonte de alimentação dos rebanhos no Nordeste. Essas pastagens apresentam baixa capacidade de suporte e, no semi-árido, são qualitativamente insuficientes para a manutenção de um elevado número de animais, uma forma eficiente de nivelar a capacidade de suporte durante todo o ano é a formação de pastagem cultivada.

O sistema de produção lotação rotativa em pastagem irrigada apresenta uma série de vantagens quando comparado com o sistema praticado atualmente, tais como, nenhuma dependência do uso de pastagens nativas, giro mais rápido do capital empatado, obtenção de maior taxa de desfrute do rebanho, diminuição da taxa de mortalidade.

O rebanho mundial ovino é da ordem de um milhão de cabeças, apresentando um decréscimo médio anual de 1,18\% nos últimos 12 anos. No Brasil, o efetivo da região sul, onde predominam raças lanadas, observou-se uma queda de 50\% entre 1980 e 2001 enquanto nas regiões onde predominam as raças deslanadas, se verifica aumentos de efetivo, no Nordeste de 13,5\% (COUTO 2003).

No Brasil os ovinos e caprinos são criados em todos os estados. Segundo dados do IBGE 2003, os maiores efetivos estão no Rio Grande do Sul, Bahia, Ceará e Piauí respectivamente. A maior parte dos rebanhos ovinos se concentra nas regiões Sul, $31.75 \%$ e Nordeste, 56,55\%,

O aumento mundial médio do consumo de carne ovina é de 0,45\%, 
mostrando que o mercado continua em expansão. Destaca-se a Europa como maior comprador de carne ovina com a importação de US \$1,4 bilhão, seguido do continente americano com a importação de US \$ 384,2 milhões e a Ásia com US\$362,1 milhões (COUTO 2003).

$\mathrm{O}$ atual crescimento do consumo de carne ovina no Brasil está direcionado para nichos de mercado existente nas grandes cidades, onde o poder aquisitivo da população é maior, exige, porém, qualidade, cortes especiais e continuidade de abastecimento (MEDEIROS 2001).

Segundo Júnior (2003), em torno de $50 \%$ da carne ovina consumida no País é importada do Uruguai, Argentina e Nova Zelândia. Existem cerca de 20 abatedouros/frigoríficos instalados no Nordeste e todos apresentam ociosidade (LEITE, 2003), mostrando que apesar do crescimento no número de cabeças de ovinos, o rebanho brasileiro não consegue abastecer o mercado interno, abrindo espaço para a importação.

Portanto, apesar da criação de ovinos ser tradição no Sul e no Nordeste, a produção brasileira não tem conseguido atender à sua demanda interna. Um manejo reprodutivo e sanitário adequado associado aos princípios básicos na criação destes animais possibilitará o uso mais eficiente dos recursos forrageiros disponíveis, transformando a ovinocultura em uma alternativa de renda viável para os produtores rurais (SORIO, 2004). A criação de pequenos ruminantes em pastagem de boa qualidade é, geralmente, a forma mais econômica para produzir carne.

\subsection{Objetivos:}

Os objetivos deste artigo são:

a) Proporcionar aumento da produtividade, a expansão da renda, a melhoria do emprego, a fixação do homem ao campo e o incentivo do produtor para investir em novas técnicas de produção;

b) Estimar os custos de produção de ovinos em sistema de pastejo rotacionado;

c) Analisar as potencialidades técnicas e econômicas da criação de ovinos na região do Vale do Curú, Estado do Ceará, para promover a elevação da produção e produtividade. 


\section{Material e Métodos}

Os dados experimentais foram coletados junto à fazenda experimental do Vale do Curú, situada no município de Pentecostes - Ceará - e ao departamento de Zootecnia do Centro de Ciências Agrárias (CCA) da Universidade Federal do Ceará (UFC). Os dados fora obtidos do trabalho "Morfofisiológica do dossel e desempenho produtivo de ovinos em Panicum Maximum (Jacq.) cv. Tanzânia sob três períodos de descanso", desenvolvido por Silva (2004).

Foram utilizados 100 ovinos deslanados mestiços (Santa Inês x SRD), sendo 48 animais de prova e 52 de equilíbrio, com peso vivo inicial em torno de $20 \mathrm{~kg}$.

Foram empregados três períodos de descanso do pasto, que constituíram os tratamentos. Tais períodos de descanso foram estabelecidos em função do tempo necessário para a formação de 1,5, 2,5 e 3,5 novas folhas após o pastejo; tratamento 1 - tempo para se formarem em média 1,5 folha por perfilho (média de 17,3 dias) ; tratamento 2 - tempo para se formarem em média 2,5 folhas por perfilho (média de 26,1 dias) e tratamento 3 - tempo para se formarem em média 3,5 folhas por perfilho (média de 36,9 dias).

O delineamento experimental foi o de casualização completa, com quatro, seis e oito piquetes para cada uma de duas repetições de campo dos tratamentos 1,5, 2,5 e 3,5 novas folhas, respectivamente, envolvendo 36 piquetes, de áreas inversamente proporcionais à duração dos períodos de descanso. A área variável dos piquetes por tratamento foi adotada para garantir em todos os tratamentos a mesma pressão de pastejo a fim de permitir estimativas válidas de efeito dos tratamentos sobre o desempenho animal (ganho de peso, kg vivo/ovino) (MOTT, 1960).

Oito animais de prova sorteados a cada tratamento, pastejaram durante cinco dias em cada piquete do respectivo tratamento em sistema rotativo. Ovinos extras (animais de equilíbrio) foram conduzidos aos piquetes em pastejo, quando necessário, para garantir rebaixamento da vegetação para um índice de área foliar (IAF) em torno de 1, ao final do quinto dia. Uma área extra de 1,03 ha foi utilizada para acomodar os animais de equilíbrio, assim como os animais de prova, de qualquer tratamento, até que se completasse o período de descanso previsto para cada piquete experimental. Durante o período de descanso as caracte- 
rísticas morfofisiológicas do capim Tanzânia foram acompanhadas. A pesagem dos animais de prova foi efetuada no início e final de cada ciclo de pastejo com o objeto de determinar a produção por ciclo.

A análise foi feita com base nos valores referentes a 1,3 e 5 hectares, com vistas a determinar o nível de produção mínimo para tornar o empreendimento viável. O horizonte da análise foi de 10 anos, período de depreciação do sistema de irrigação. Para cada tratamento foram comparados os custos da utilização de cerca de tela e cerca elétrica. No primeiro ano a produção fica restrita a 8 meses, visto que são necessários 4 meses para a implantação e formação da pastagem.

Foi utilizada como medida de eficiência a relação benefício custo RB/ CT que expressa o desempenho global de todos os fatores de produção.

$\mathrm{RB} / \mathrm{CT}=\Sigma \mathrm{Ri}^{0} / \Sigma\left(\mathrm{Ci}^{0}+\mathrm{I}\right)$, onde, $\mathrm{Ri}=$ receita no ano $\mathrm{i}$ até o ano $0 ; \mathrm{Ci}=$ custos no ano $\mathrm{i}$ até o ano 0 ; $\mathrm{I}=$ investimento

Para cada tratamento foi determinado o valor presente líquido, que leva em consideração o efeito do tempo sobre os valores monetários (valores reais) utilizando-se a taxa média de juros do mercado (custo de oportunidade do capital). O VPL é a soma de todas as receitas líquidas atualizadas a uma taxa de desconto adequada.

Por definição, a taxa interna de retorno é aquele valor que torna o valor presente líquido igual a zero, mostra a taxa máxima que o projeto pode suportar.

Com a análise de sensibilidade procurou-se incorporar na análise as questões de risco e incerteza, associados com os valores das variáveis importantes.

Para o cálculo da depreciação, utilizou-se o método linear ou das cotas fixas, que proporciona depreciação constante, cujo valor é determinado através da seguinte fórmula:

(vi - vf)/n, onde:

vi é o valor inicial,

vf é o valor final, que corresponde ao valor do bem de capital após sua vida útil, n é o número de anos de duração do capital (vida útil). 
Foi estimado o custo total de implantação e manutenção para cada tratamento, para isso foram coletados dados referentes ao preparo do solo, energia, cercas, mão-de-obra, sementes, aquisição e montagem do sistema de irrigação.

Considerou-se como gasto com mão de obra de manutenção um funcionário em regime permanente para manejar um rebanho composto por 300 animais, (realizar as operações de transferência dos animais nos piquetes, limpeza das instalações, manutenção do sistema de irrigação). Considerou-se como remuneração da mão-de-obra um salário mínimo vigente em 2004. O centro de manejo foi dimensionado para permitir 1,0 $\mathrm{m}^{2}$ de área coberta por animal além de um pequeno curral de manejo que dispusesse de $0,75 \mathrm{~m}^{2}$ por animal. Para o cálculo da receita total foi considerado um preço médio de $\mathrm{R}$ 2,60 o quilo vivo.

\section{Resultados e Discussão}

A estimativa de custos de implantação para todos os tratamentos encontra-se nas Tabelas 1 a 3 do anexo, onde se pode observar que os sistemas que utilizam cerca elétrica apresentam menor custo de implantação que o sistema que utiliza cerca de tela. No entanto, o seu custo de manutenção é maior (Tabelas 4 a 6 do anexo), dessa forma não houve diferença significativa entre os indicadores econômicos dos dois sistemas (Tabelas 9 e 10 do anexo).

Pode-se observar nas referidas Tabelas 1 a 3 que para todos os tratamentos o item que mais onerou a estrutura de custo de implantação foi a irrigação, cuja participação no custo total para a exploração de 1 ha chega a $57,32 \%$ para todos os tratamentos com a utilização de cerca elétrica, e em torno de 47,80\% considerando a utilização de cerca de tela. Na exploração de 3 ha o percentual se eleva para 62,95\% para cerca elétrica e 54,21\% para cerca de tela. Considerando a exploração de 5 ha, o percentual passa a 63,09\% para cerca elétrica e 55,51\% para cerca de tela. Pode-se observar ainda que o custo percentual da cerca se torna relativamente menos onerosa com o aumento da área; esse fato evidencia a ineficiência da utilização desse fator de produção na exploração de apenas um hectare.

O custo com mão de obra representa mais de $53 \%$ do custo total de 
manutenção da atividade em todos os tratamentos (Tabelas 4 a 6), esta despesa será tanto maior quanto menor a área explorada, visto que esse item é influenciado pelo grau de utilização, um número pequeno de animais pode deixar mão-de-obra ociosa, elevando o custo do sistema.

A diferença no custo de manutenção entre os tratamentos é pequena e deve-se basicamente à depreciação da cerca (Tabelas 4 a 6). O sistema que utiliza cerca elétrica apresenta maior custo de manutenção visto que há necessidade de retirada de plantas do pé da cerca visando evitar perda de corrente elétrica, no entanto, o sistema de cerca de tela apresenta maior custo com a depreciação, de forma que não se observa diferença significativa no custo de manutenção entre os sistemas.

A exploração de um hectare se mostrou economicamente inviável para todos os tratamentos testados, observou-se que os custos totais são maiores que as receitas totais auferidas (Tabelas 7 e 8), isso se dá em função dos custos fixos que são elevados frente ao nível de produção.

O tratamento 1,5 folha apresentou os melhores indicadores financeiros (Tabelas 9 e 10), no entanto, SILVA, (2004) concluiu que há elevado risco de degradação da pastagem. Pastejos muito freqüentes, antes da estabilização do número de folhas, exaurem as reservas de carboidratos solúveis da planta (FULKERSON e SLACK, 1994) e prejudicam o perfilhamento (FULKERSON e SLACK, 1995), comprometendo a persistência da pastagem, além de apresentar rendimento inferior devido à menor produção de forragem (VIEIRA e GOMIDE, 1968). Há necessidade de novos estudos para determinar a vida útil da pastagem visto que sob condições de pastejo muito freqüente é menor, portanto, inferior ao adotado no estudo (10 anos), dessa forma os indicadores financeiros devem ser inferiores aos encontrados.

O tratamento 3,5 folhas sob as condições estudadas não deve ser utilizado, visto que os custos são superiores às receitas auferidas (Tabelas 7 e 8), este resultado se dá em função da qualidade da pastagem que é inferior aos outros tratamentos, refletindo diretamente no ganho de peso dos animais. Embora os custos de produção do tratamento 3,5 folhas sejam equivalentes aos outros dois tratamentos (Tabelas 1 a 3), as receitas auferidas foram inferiores aos obtidos nos tratamentos 1,5 folha e 2,5 folhas (Tabelas 7 e 8).

Desta forma, sob o ponto de vista biológico, ambiental e econômico, o 
melhor resultado foi observado no tratamento 2,5 folhas que apresentou os melhores indicadores econômicos (Tabela 10). No entanto, observou-se que o tratamento só proporciona retorno econômico com a exploração de áreas acima de 5 ha. Para a exploração de 3 ha o valor presente líquido é negativo mesmo para as menores taxas de desconto e a relação benefício/ custo é menor que 1. Considerando a exploração de 5 ha, para uma taxa de desconto de $10 \%$ o valor presente líquido foi superior a zero, portanto, o tratamento totaliza um benefício superior ao custo de oportunidade do capital, ou seja, os benefícios são suficientes para compensar os custos de oportunidade de sacrificar alternativas de investimento. A TIR se mostrou maior do que a taxa de juros de oportunidade do capital 10\%. O retorno do projeto compensa o custo de oportunidade do dinheiro e gerará um rendimento adicional, considera-se então o projeto como um investimento viável. No entanto, a Rb/c do tratamento mostrou que o valor presente dos benefícios é praticamente igual aos custos. Considerando uma taxa de juros de $10 \%$ para cada uma unidade monetária de custo, o empreendimento gera apenas 1,01 de receita (Tabela 10). A análise de sensibilidade foi feita apenas para os tratamentos que apresentaram retorno econômico. Para o tratamento 2,5 folhas foi feita análise de sensibilidade apenas para 5 ha visto que áreas menores não proporcionam retorno econômico. 0 tratamento 1,5 folha apresentou boa estabilidade (Tabelas 11 e 12), na situação de uma queda de $15 \%$ nas receitas ou elevação de $15 \%$ nos custos, o tratamento permaneceu com todos os indicadores favoráveis à consecução do projeto. Uma queda de $15 \%$ nas receitas ou aumento de até $15 \%$ nos custos resulta numa queda da $\mathrm{Rb} / \mathrm{c}$ que se aproxima de 1 , o que representa que os custos e receitas auferidas pelo tratamento se equivalem. A TIR permanece superior à taxa de custo de oportunidade do capital e o VPL superior a zero. Esse resultado evidencia a importância da velocidade de ganho de peso dos animais, visto que a diferença entre os custos de produção dos tratamentos é pequena.

Na Tabela 13 pode-se observar que o tratamento 2,5 folhas com exploração de 5 ha não possui boa estabilidade, qualquer elevação nos custos ou redução nas receitas torna o empreendimento inviável. Esse resultado evidencia que o sistema só proporcionará retorno econômico com produção em escala, exploração de áreas menores de 5 ha é inviável economicamente. 


\section{Conclusões}

Dada a variabilidade climática e de solo existente no Nordeste do Brasil, não é possível generalizar os resultados para toda a região, no entanto, estes podem ser utilizados como indicativo de resposta em regiões que apresentem características edafoclimáticas semelhantes.

Tomando-se por base as condições em que foi conduzido o experimento e de acordo com as análises e discussões apresentadas, pode-se concluir para a região do Vale do Curú, Estado do Ceará, que:

A exploração de 1 ha é inviável para todos os tratamentos testados;

O tratamento 3,5 folhas sob não deve ser utilizado;

O tratamento 1,5 folha apresentou os melhores indicadores financeiros, no entanto, apresentou elevado risco de degradação da pastagem. Há necessidade de novos estudos para determinar a vida útil da pastagem sob as condições de pastejo testada, que deve ser inferior ao adotado no estudo (10 anos);

O melhor resultado sob o ponto de vista, econômico, biológico e ambiental foi o tratamento com 2,5 folhas com exploração de no mínimo 5ha;

De acordo com os resultados encontrados, o produtor da região pode escolher o tipo de cerca de acordo com as condições locais da propriedade;

Á medida que se aumenta a área explorada de 1 para 5 ha, eleva-se a estabilidade do sistema e o retorno econômico, no entanto, há necessidade de novos estudos para determinar a área que maximiza a receita.

Para que o produtor tenha retorno econômico utilizando o sistema testado, há necessidade de utilização de animais de ótimo potencial genético que apresentem elevado ganho de peso, minimização dos custos através de utilização ótima dos fatores de produção, principalmente, mão de obra - a qual representa mais de $50 \%$ dos custos de produção - e trabalhar com economia de escala com a exploração de áreas superiores a 5 ha. 


\section{Referencias Bibliográficas}

COUTO, A.F.A.d'. Dimensionamento do Mercado de Carne Ovina e Caprina no Brasil. In: II Simpósio Internacional Sobre Caprinos e Ovinos de Corte. Anais...João Pessoa, PB. 2003, p.71-81.

FULKERSON, W.J., SLACK, K. Leaf number as a criterion for determining defoliation time for Lolium perenne. 1. Effect of water-soluble carbohydrates and senescence. Grass Forage Sci., v.49, n.4, p.373-377, 1994.

FULKERSON, W.J., SLACK, K. Leaf number as a criterion for determining defoliation time for Lolium perenne. 2. Effect of defoliation frequency and height. Grass Forage Sci., v.50, n.1, p.16-20, 1995.

JUNIOR, E.V.H; AS, J.L; ARAUJO, G.G.L. Articulação dos segmentos da cadeia produtiva de caprinos e ovinos - os fluxos alternativos de comercialização. In: II Simpósio Internacional Sobre Caprinos e Ovinos de Corte. Anais... João Pessoa, PB. 2003, p.83-93.

LEITE, E.R. Ovinocaprinocultura: A modernização do Agronegócio. Disponível em: www.capritec.com.br. Acesso em: 13/10/2004.

MEDEIROS, J.X. de. Situação atual das cadeias produtivas. In: "Apoio à cadeia produtiva da Ovinocaprinocultura Brasileira”. Relatório Final. MCT/CNPq. Brasília, DF. 2001.

MOTT, G.O. Grazing pressure and the measurement of pasture production. In: INTERNATIONAL GRASSLAND CONGRESS, 8, 1960, City. Proceedings... City: s. ed., 1960. p.606-611.

SILVA, R. G. da. Morfofisiológica do dossel e desempenho produtivo de ovinos em Panicum maximum (Jacq.) cv Tanzânia sob três períodos de descanso. Fortaleza, 2004. 114f. Dissertação (Mestrado em Zootecnia), Universidade Federal do Ceará (UFC).

VIEIRA, L.M., GOMIDE, J.A. Composição química e produção forrageira de três variedades de capim-elefante. Ceres, v.15, n.86, p. 245-260, 1968.

SORIO, A. Mercado de carne de caprinos e ovinos. Disponível em: < www. caroata.com.br/asp/materiatecnica.asp > Acesso em: 31/10/2004. 

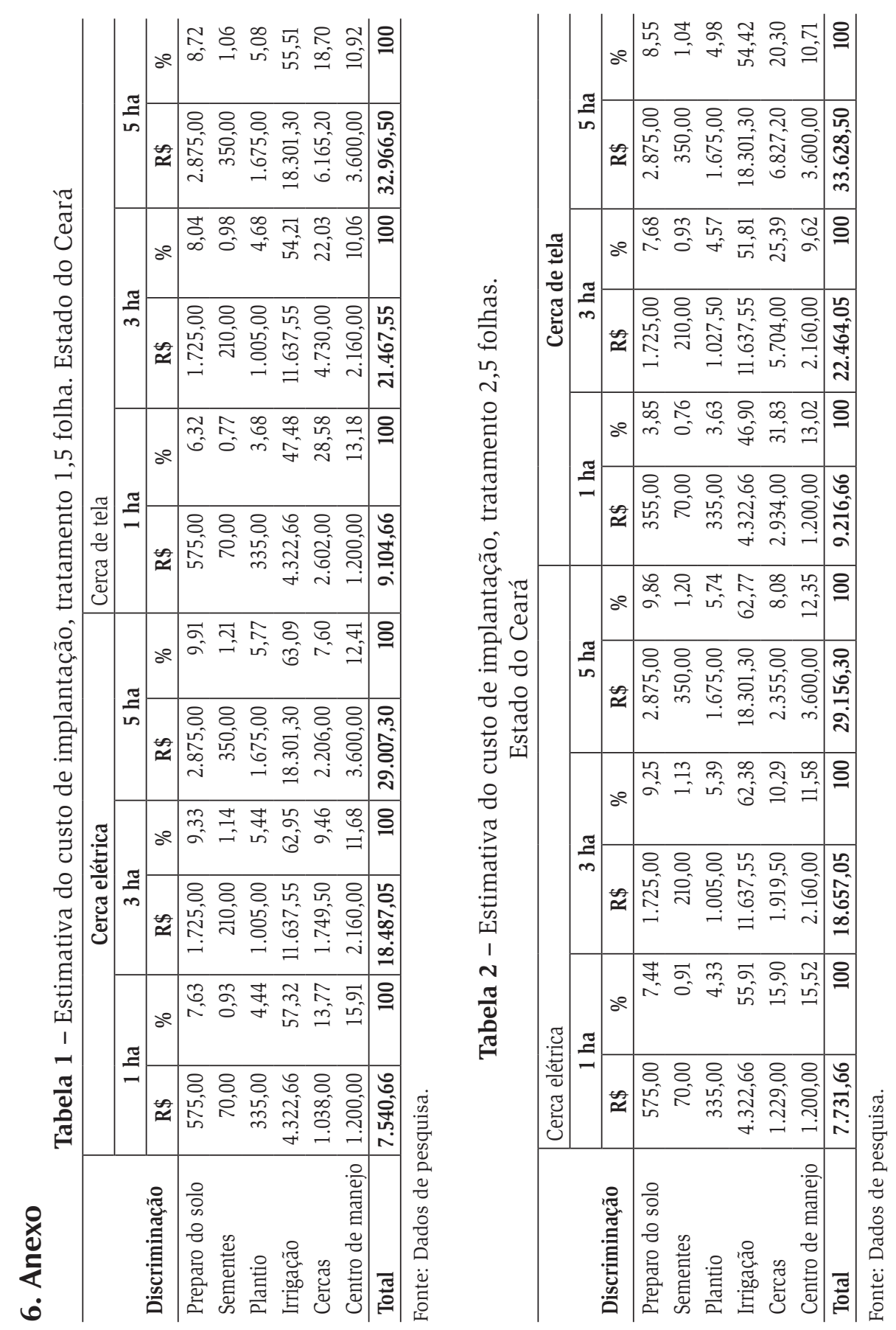

RER, Rio de Janeiro, vol. 44, no 04, p. 801-818, out/dez 2006 - Impressa em dezembro 2006 

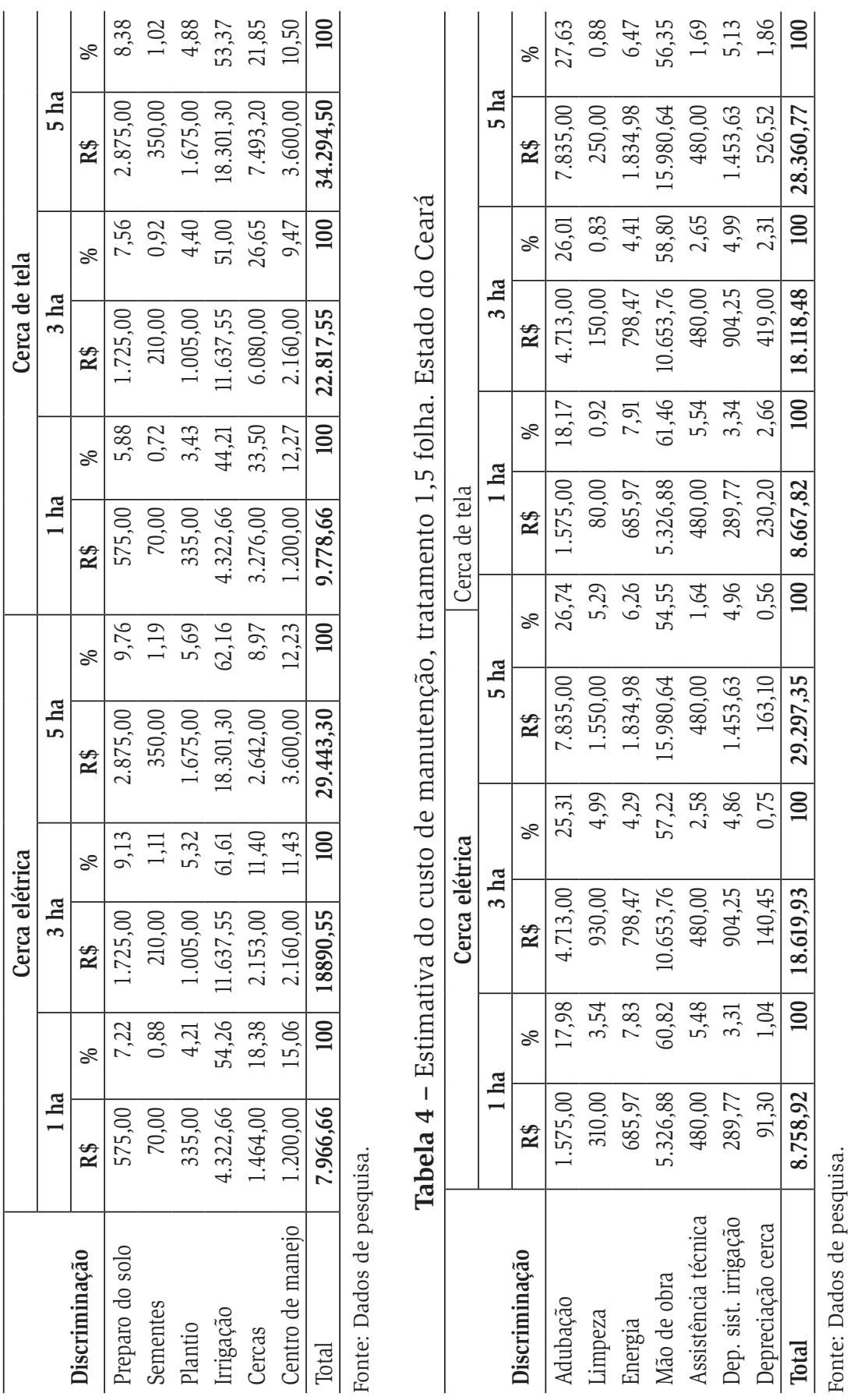
814 - Análise econômica da produção de ovinos em lotação rotativa em pastagem de capim tanzânia (Panicum maximum (JACQ))
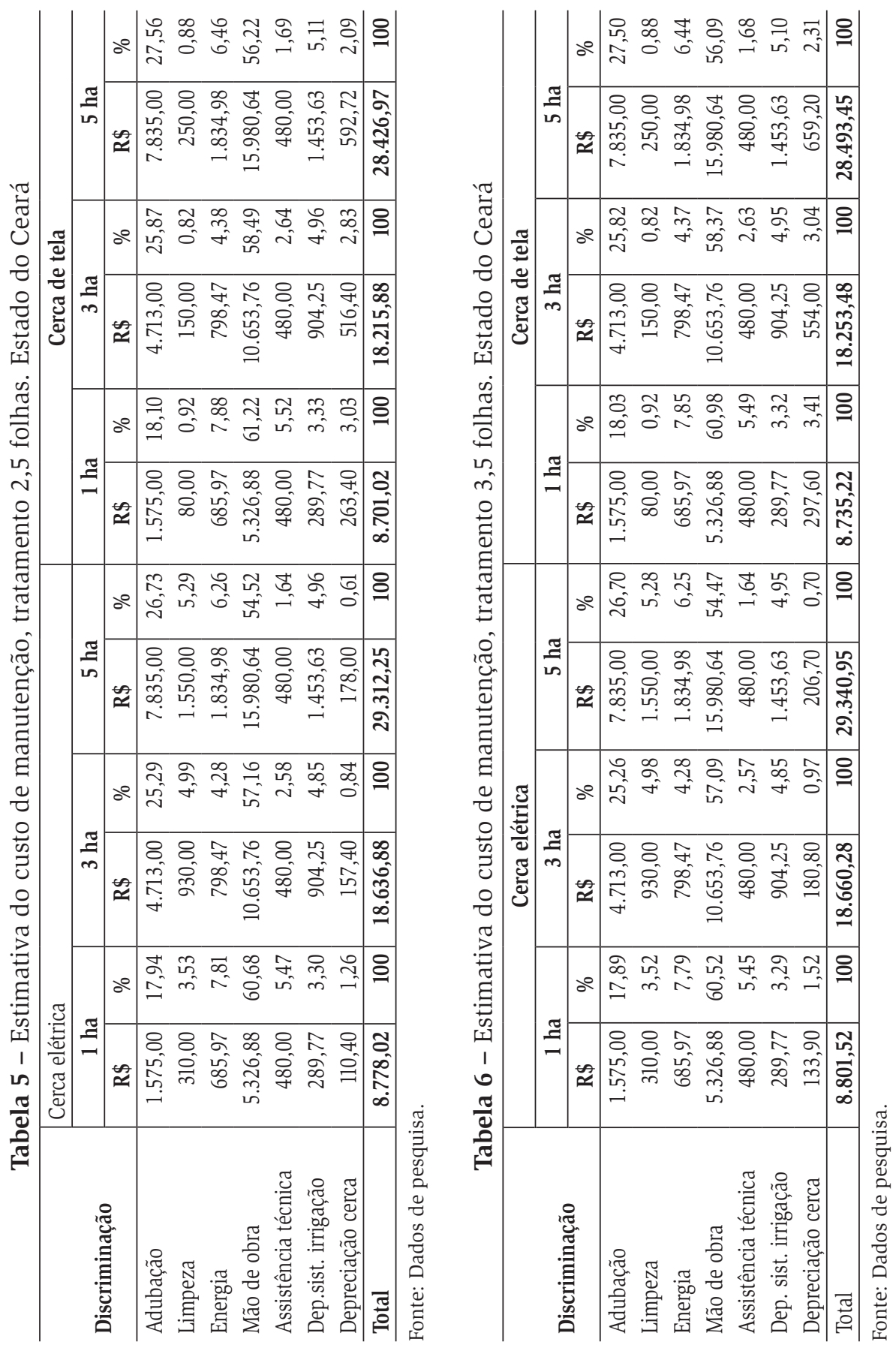

RER, Rio de Janeiro, vol. 44, no 04, p. 801-818, out/dez 2006 - Impressa em dezembro 2006 
Tabela 7 - Receitas e Custos totais, tratamento, para primeiro e segundo ano, cerca elétrica

\begin{tabular}{|c|c|c|c|c|c|c|c|}
\hline \multirow{3}{*}{ Trat. } & \multirow{3}{*}{ Anos } & \multicolumn{6}{|c|}{ Cerca elétrica } \\
\hline & & \multicolumn{2}{|c|}{ 1ha } & \multicolumn{2}{|c|}{3 ha } & \multicolumn{2}{|c|}{5 ha } \\
\hline & & RT & CT & RT & CT & RT & CT \\
\hline \multirow[b]{2}{*}{1,5 folha } & $1^{*}$ & $5.419,96$ & $14.384,60$ & $16.259,67$ & $31.784,46$ & $27.099,80$ & $49.590,37$ \\
\hline & $2-8$ & $8.129,94$ & $8.758,92$ & $24.389,82$ & $18.619,93$ & $40.649,70$ & $29.297,35$ \\
\hline \multirow{3}{*}{2,5 folhas } & 1 & $4.585,85$ & $14.594,70$ & $13.757,56$ & $31.971,41$ & $22.929,27$ & $49.754,27$ \\
\hline & $2-8$ & $6.878,77$ & $8.778,02$ & $20.636,30$ & $18.636,88$ & $34.393,84$ & $29.312,25$ \\
\hline & 1 & $2.931,34$ & $14.754,20$ & $8.794,03$ & $32.228,32$ & $14.656,72$ & $50.069,97$ \\
\hline 3,5 folhas & $2-8$ & $4.396,99$ & $8.801,52$ & $13.190,97$ & $18.660,28$ & $21.984,95$ & $29.340,95$ \\
\hline
\end{tabular}

Fonte: Dados de pesquisa.

Tabela 8 - Receitas e Custos totais, tratamento, para primeiro e segundo ano, cerca de tela

\begin{tabular}{|c|c|c|c|c|c|c|c|}
\hline \multirow{3}{*}{ Trat. } & \multirow{3}{*}{ Anos } & \multicolumn{6}{|c|}{ Cerca de tela } \\
\hline & & \multicolumn{2}{|c|}{1 há } & \multicolumn{2}{|c|}{3 ha } & \multicolumn{2}{|c|}{5 ha } \\
\hline & & RT & CT & RT & CT & RT & CT \\
\hline \multirow[b]{2}{*}{1,5 folha } & $1^{*}$ & $5.419,96$ & $16.067,50$ & $16.256,67$ & $34.983,52$ & $27.099,80$ & $53.812,99$ \\
\hline & $2-8$ & $8.129,94$ & $8.667,82$ & $24.389,82$ & $18.118,48$ & $40.649,70$ & $28.360,77$ \\
\hline \multirow{3}{*}{2,5 folhas } & 1 & $4.585,85$ & $16.212,70$ & $13.757,56$ & $36.077,41$ & $22.929,27$ & $54.541,19$ \\
\hline & $2-8$ & $6.878,77$ & $8.701,02$ & $20.636,30$ & $18.215,88$ & $34.393,84$ & $28.426,97$ \\
\hline & 1 & $2.931,34$ & $16.808,90$ & $8.794,03$ & $36.468,52$ & $14.656,72$ & $55.273,67$ \\
\hline 3,5 folhas & $2-8$ & $4.396,99$ & $8.735,22$ & $13.190,97$ & $18.253,48$ & $21.984,95$ & $28.493,45$ \\
\hline
\end{tabular}

Fonte: Dados de pesquisa.

* Obs: Os demais anos, em um horizonte de 8 anos apresentam mesmo custo e receitas totais que o segundo ano. 
Tabela 9 - Tratamento 1,5 folha, indicadores econômicos, relação benefício custo, valor presente líquido e taxa interna de retorno

\begin{tabular}{|c|c|c|c|c|c|c|c|c|}
\hline \multirow{3}{*}{$\begin{array}{c}\text { Taxa } \\
\text { de } \\
\text { desconto }\end{array}$} & \multicolumn{4}{|c|}{ Cerca elétrica } & \multicolumn{4}{|c|}{ Cerca de tela } \\
\hline & \multicolumn{2}{|c|}{3 ha } & \multicolumn{2}{|c|}{5 ha } & \multicolumn{2}{|c|}{3 ha } & \multicolumn{2}{|c|}{5 ha } \\
\hline & $\mathrm{B} / \mathrm{C}$ & VPL & $\mathrm{B} / \mathrm{C}$ & VPL & $\mathrm{B} / \mathrm{C}$ & VPL & $\mathrm{B} / \mathrm{C}$ & VPL \\
\hline $4 \%$ & 1,16 & $26.323,32$ & 1,23 & $59.248,00$ & 1,16 & $26.832,35$ & 1,24 & $62.172,19$ \\
\hline $6 \%$ & 1,15 & $22.377,57$ & 1,22 & $51.343,98$ & 1,15 & $22.577,24$ & 1,23 & $53.653,14$ \\
\hline $8 \%$ & 1,14 & $18.999,14$ & 1,21 & $44.561,38$ & 1,14 & $18.937,51$ & 1,22 & $46.346,65$ \\
\hline $10 \%$ & 1,13 & $16.094,68$ & 1,19 & $38.716,26$ & 1,12 & $15.811,77$ & 1,20 & $40.053,68$ \\
\hline $12 \%$ & 1,12 & $13.588,06$ & 1,18 & $33.658,56$ & 1,11 & $13.117,34$ & 1,19 & $34.611,87$ \\
\hline $14 \%$ & 1,11 & $11.416,87$ & 1,17 & $29.265,24$ & 1,10 & $10.786,43$ & 1,18 & $29.888,09$ \\
\hline $16 \%$ & 1,09 & $9.529,71$ & 1,16 & $25.434,94$ & 1,09 & $8.763,24$ & 1,16 & $25.772,68$ \\
\hline $18 \%$ & 1,08 & $7.884,05$ & 1,15 & $22.083,76$ & 1,07 & $7.001,58$ & 1,15 & $22.174,87$ \\
\hline $20 \%$ & 1,07 & $6.444,54$ & 1,14 & $19.141,98$ & 1,06 & $5.463,09$ & 1,14 & $19.019,23$ \\
\hline TIR & \multicolumn{2}{|c|}{$34,60 \%$} & \multicolumn{2}{|c|}{$48,38 \%$} & \multicolumn{2}{|c|}{$30,43 \%$} & \multicolumn{2}{|c|}{$44,31 \%$} \\
\hline
\end{tabular}

Fonte: Dados de pesquisa.

Tabela 10 - Tratamento 2,5 folhas. Indicadores econômicos, relação benefício/custo, valor presente líquido e taxa interna de retorno

\begin{tabular}{c|c|c|c|c|c|c|c|c}
\hline \multirow{2}{*}{$\begin{array}{c}\text { Taxa } \\
\text { de } \\
\text { desconto }\end{array}$} & \multicolumn{4}{|c|}{ Cerca elétrica } & \multicolumn{4}{c}{ Cerca de tela } \\
\cline { 2 - 9 } & \multicolumn{2}{|c|}{$\mathbf{3}$ ha } & \multicolumn{2}{|c|}{$\mathbf{5}$ ha } & \multicolumn{2}{|c}{$\mathbf{3}$ ha } & \multicolumn{2}{c}{$\mathbf{5}$ ha } \\
\hline $\mathbf{4} \%$ & 0,98 & - & 1,04 & $10.536,83$ & 0,97 & - & 1,05 & $12.263,21$ \\
$\mathbf{6} \%$ & 0,97 & - & 1,03 & $7.300,39$ & 0,96 & - & 1,04 & $8.464,99$ \\
$\mathbf{8} \%$ & 0,96 & - & 1,02 & $4.554,74$ & 0,95 & - & 1,02 & $5.243,01$ \\
$\mathbf{1 0} \%$ & 0,95 & - & 1,01 & $2.218,18$ & 0,94 & - & 1,01 & $2.501,30$ \\
$\mathbf{1 2} \%$ & 0,94 & - & 1,00 & 224,09 & 0,93 & - & 1,00 & 161,66 \\
$\mathbf{1 4} \%$ & 0,93 & - & 0,99 & - & 0,92 & - & 0,99 & - \\
$\mathbf{1 6} \%$ & 0,92 & - & 0,98 & - & 0,91 & - & 0,98 & - \\
$\mathbf{1 8} \%$ & 0,91 & - & 0,97 & - & 0,90 & - & 0,97 & - \\
$\mathbf{2 0} \%$ & 0,91 & - & 0,96 & - & 0,89 & - & 0,96 & - \\
\hline TIR & \multicolumn{2}{|c|}{$-0,24 \%$} & \multicolumn{2}{|c|}{$12,25 \%$} & \multicolumn{2}{|c|}{$-0,48 \%$} & \multicolumn{2}{c}{$12,15 \%$} \\
\hline
\end{tabular}

Fonte: Dados de pesquisa. 
Tabela 11 - Análise de sensibilidade tratamento 1,5 folha, cerca elétrica

\begin{tabular}{|c|c|c|c|c|c|c|}
\hline \multirow{3}{*}{ Descrição } & \multicolumn{6}{|c|}{ Cerca elétrica } \\
\hline & \multicolumn{3}{|c|}{3 ha } & \multicolumn{3}{|c|}{5 ha } \\
\hline & $\mathrm{B} / \mathrm{C}$ & VPL & TIR & $\mathrm{B} / \mathrm{C}$ & VPL & TIR \\
\hline Receitas e custos normais & 1,13 & $16.094,68$ & 34,60 & 1,19 & 38716,26 & 48,38 \\
\hline Receitas - $5 \%$ e custos normais & 1,07 & $8.970,99$ & 23,76 & 1,14 & $26.843,42$ & 36,21 \\
\hline Receitas normais e custos $+5 \%$ & 1,07 & $9.775,72$ & 24,28 & 1,14 & $28.779,24$ & 36,77 \\
\hline Receitas - 10 e custos normais & 1,01 & $1.847,29$ & 12,91 & 1,08 & $14.970,59$ & 24,64 \\
\hline Receitas normais e custos $+10 \%$ & 1,02 & $3.456,76$ & 14,92 & 1,09 & $18.842,21$ & 26,72 \\
\hline Receitas normais e custos $+15 \%$ & 0,98 & - & 5,95 & 1,04 & $8.905,19$ & 17,67 \\
\hline Receitas - $15 \%$ e custos normais & 0,96 & - & 1,14 & 1,02 & $3.097,75$ & 13,11 \\
\hline Receitas normais e custos $+20 \%$ & 0,94 & - & - & 1,00 & & 9,12 \\
\hline Receitas -10 e custos $+10 \%$ & 0,92 & - & - & 0,98 & & 5,35 \\
\hline
\end{tabular}

Fonte: Dados de pesquisa.

Tabela 12 - Analise de sensibilidade tratamento 1,5 folha, cerca de tela

\begin{tabular}{l|c|c|c|c|c|c}
\hline \multirow{2}{*}{\multicolumn{1}{c|}{ Descrição }} & \multicolumn{6}{|c}{ Cerca de tela } \\
\cline { 2 - 7 } & \multicolumn{3}{|c|}{$\mathbf{3}$ ha } & \multicolumn{3}{c}{$\mathbf{5}$ ha } \\
\cline { 2 - 7 } & B/C & VPL & TIR & B/C & VPL & TIR \\
\hline Receitas e custos normais & 1,12 & $15.811,77$ & 30.43 & 1,20 & $40.053,68$ & 44,31 \\
Receitas - 5\% e custos normais & 1,07 & $8.688,08$ & 21,31 & 1,14 & $28.180,85$ & 33,90 \\
Receitas normais e custos + 5\% & 1,07 & $9.478,67$ & 21,75 & 1,15 & $30.183,53$ & 34,38 \\
Receitas - 10 e custos normais & 1,01 & $1.564,39$ & 12,09 & 1,08 & $16.308,01$ & 23,88 \\
Receitas normais e custos + 10\% & 1,02 & $3.145,56$ & 13,80 & 1,09 & $20.313,38$ & 25,69 \\
Receitas normais e custos + 15\% & 0,98 & - & 6,16 & 1,05 & $10.443,23$ & 17,82 \\
Receitas - 15\% e custos normais & 0,96 & - & 2,16 & 1,02 & $4.435,17$ & 13,86 \\
Receitas normais e custos + 20\% & 0,94 & - & - & 1,00 & 573,087 & 10,42 \\
Receitas - 10 e custos + 10\% & 0,92 & - & - & 0,98 & - & 7,20 \\
\hline
\end{tabular}

Fonte: Dados de pesquisa. 
Tabela 13 - Análise de sensibilidade tratamento 2,5 folhas, exploração de 5 ha

\begin{tabular}{l|c|c|c|c|c|c}
\hline \multirow{2}{*}{\multicolumn{1}{c|}{ Descrição }} & \multicolumn{3}{c|}{ Cerca elétrica } & \multicolumn{3}{c}{ Cerca de tela } \\
\cline { 2 - 7 } & \multicolumn{3}{|c|}{5 ha } & \multicolumn{3}{c}{$\mathbf{5}$ ha } \\
\cline { 2 - 7 } & B/C & VPL & TIR & B/C & VPL & TIR \\
\hline Receitas e custos normais & 1,01 & $2.218,18$ & 12,25 & 1,01 & $2.501,30$ & 12,15 \\
Receitas - 5\% e custos normais & 0,96 & - & 1,60 & 0,96 & - & 3,20 \\
Receitas normais e custos + 5\% & 0,96 & - & 2,14 & 0,96 & - & 3,65 \\
Receitas - 10 e custos normais & 0,91 & - & - & 0,91 & - & - \\
Receitas normais e custos + $\mathbf{1 0} \%$ & 0,92 & - & - & 0,92 & - & - \\
Receitas normais e custos + $\mathbf{1 5 \%}$ & 0,88 & - & - & 0,88 & - & - \\
Receitas - 15\% e custos normais & 0,86 & - & - & 0,86 & - & - \\
Receitas normais e custos + 20\% & 0,84 & - & - & 0,84 & - & - \\
Receitas - $\mathbf{1 0}$ e custos $+\mathbf{1 0} \%$ & 0,83 & - & - & 0,83 & - & - \\
\hline
\end{tabular}

Fonte: Dados de pesquisa.

Recebido em outubro de 2005 e revisto em agosto de 2006. 